\title{
Circulating microRNAs as promising diagnostic biomarkers for pancreatic cancer: a systematic review
}

This article was published in the following Dove Press journal:

OncoTargets and Therapy

\author{
Jinru Xue ${ }^{1, *}$ \\ Erna Jia ${ }^{2, *}$ \\ Na Ren' \\ Andrew Lindsay ${ }^{3,4}$ \\ Haixin $\mathrm{Yu}^{\mathrm{l}, 5}$ \\ 'Department of Thoracic Surgery, China- \\ Japan Union Hospital of Jilin University, \\ Changchun, People's Republic of China; \\ ${ }^{2}$ Department of Gastroenterology, \\ China-Japan Union Hospital of Jilin \\ University, Changchun, People's Republic \\ of China; ${ }^{3}$ Major Cancer Biology, German \\ Cancer Research Center, Heidelberg, \\ Germany; ${ }^{4}$ Faculty of Biosciences, \\ University of Heidelberg, Heidelberg, \\ Germany; ${ }^{5}$ Medical Faculty Heidelberg, \\ University of Heidelberg, Heidelberg, \\ Germany
}

*These authors contributed equally to this work

\begin{abstract}
Pancreatic cancer (PC) is one of the most common forms of malignant tumors and causes of tumor-related death worldwide. The current prognosis of PC still remains poor due to the lack of effective early detection method. Recently, there is strong support that circulating miRNAs can be used as biomarkers for early detection of various cancers, including PC. The purpose of this review is to provide an overview of previous published studies on circulating miRNAs in plasma/serum for early detection of PC and summarize their diagnostic value. PubMed, Embase and Web of Science were systematically searched for eligible studies on circulating miRNAs for PC detection. Overall, 29 studies published between 2009 and 2018 evaluating 51 individual miRNAs (no $P$-value exceeding 0.05 ) and 13 miRNAs panels were included. Generally, the diagnostic performance of circulating miRNAs for PC detection was strong, with both the sensitivity and specificity of $36 \%$ individual miRNAs and 40\% miRNAs panels exceeding $80 \%$. Moreover, two promising miRNA panels were discovered and verified externally with all AUC values exceeding 0.95. Therefore, circulating miRNAs may hold potential to be used as noninvasive diagnostic biomarkers for PC, but large-scale studies are still needed to validate the promising miRNAs and optimize the miRNA panels. Since, the tremendous heterogeneity of studies in this field hampers translating miRNA markers into clinical practice, miRNA analytical procedures are also needed to be standardized in the future.
\end{abstract}

Keywords: pancreatic cancer, early detection, circulating microRNAs

\section{Introduction}

Pancreatic cancer (PC) is one of the most malignant tumors worldwide. The morbidity is projected to grow at a rate of $3 \%$ per year in males in the United States, ${ }^{1}$ and is predicted to become the second leading cause of total cancer-related death before $2030 .^{2}$ Currently, radical resection is always the most effective curative option for patients with localized and regional PCs. ${ }^{3}$ However, most PC patients are diagnosed with major vascular invasion or distant metastasis when radical resection is usually not available. ${ }^{4}$ Consequently, early diagnosis and effective screening of high-risk populations for $\mathrm{PC}$ is a valid approach to improve prognosis. Traditional PC imaging tests have drawbacks that are often not suitable for PC screening: computed tomography (CT) has radiation exposure and a high false positive rate ${ }^{5,6}$ magnetic resonance (MR) is expensive and prone to misdiagnosis because of its thicker scanning layer; 7,8 endoscopic ultrasound (EUS) is generally less tolerant, has certain risks, and is limited by technical difficulties. ${ }^{9}$
Correspondence: Haixin $Y u$ Department of Thoracic Surgery, ChinaJapan Union Hospital of Jilin University,

No. 126, Xiantai Avenue, Changchun 130033, People's Republic of China

Tel +86 I 5072324782

Fax +8643184995852

Email5342663II@qq.com 
In clinical, several serological biomarkers are widely used for PC diagnosis and prognosis evaluation, such as CA199, CA50, CEA, and CA242, but are usually negative in smaller pancreatic tumors, and show poor specificity for PC detection due to being overexpressed in many other diseases, such as gastroenteric tumors, bile duct cancer, and pancreatitis. $^{10-13}$

In recent years, liquid biopsy based on microRNAs (miRNAs) has become a popular research field for the early diagnosis of malignancies. MicroRNAs are highly conserved, small noncoding RNA species of 17-25 nucleotides in length ${ }^{14}$ and remarkable stable in tissue, saliva, urine, serum, plasma, and exosomes. ${ }^{15}$ Approximately $50 \%$ of miRNAs are located in tumorrelated regions. ${ }^{16}$ Aberrantly expressed miRNAs profiles were found in plasma/serum of PC patients and many PCrelated circulating miRNA candidates/panels, have been identified for PC detection with high diagnostic efficiency. Several studies have even identified abnormally expressed exosomal miRNAs in plasma specimens of PC patients, suggesting that exosomal miRNA may also be useful for PC diagnosis. ${ }^{17-19}$ Two recent prospective studies ${ }^{20,21}$ demonstrated that the closer the recruitment time to PC occurrence, then the higher the diagnostic value of miRNAs, which offers evidence for circulating miRNAs as noninvasive diagnostic markers for early stage PC. The purpose of this systematic review is to provide an overview of published studies on circulating miRNAs for early detection of PC, and to summarize their diagnostic performance.

\section{Methods}

This review was implemented in accordance with a predefined protocol, and follows the PRISMA statement for systematic reviews and meta-analysis of priority reporting items. $^{22}$

\section{Literature search strategy}

A systematic literature search was performed to identify studies assessing circulating miRNAs as biomarkers for detection of PC. We searched PubMed, ISI Web of Knowledge, and EMBASE databases for eligible articles until June 28, 2018. The combination keywords were as follows: ([pancreatic OR pancreas] AND [cancer OR carcinoma OR neoplasm OR tumor OR malignancy OR adenocarcinoma OR adenoma] AND [microRNA* OR miRNA* OR miR*] AND [detection OR diagnosis OR biomarker OR marker OR sensitivity OR specificity
OR area under the curve] AND [blood OR serum OR plasma]). Duplicate publications were removed.

\section{Eligibility criteria}

Only articles written in English were included in this review. Non-original articles such as reviews and conference abstracts were excluded because of insufficient information reported regarding the diagnostic performance of miRNA markers. We required studies that reported relevant information on the diagnostic performance of miRNA markers for human PC detection as well as the sample sizes used in the studies. Studies using treated cases before sampling or disease controls were further excluded.

\section{Data extraction and statistical analysis}

Two investigators (EJ and HY) independently filtered the relevant studies against the above-mentioned criteria. Information on first author, publication year, country, sample size, mean or median age, male proportion, specimen type, PC stage, miRNA and/or miRNAs panels investigated, diagnostic related indicators (sensitivity, specificity, AUC), and $P$-value were extracted by the two investigators independently. MicroRNAs with $P$-value greater than 0.05 were ruled out. Any inconsistency was resolved by further review and discussion among the authors. MiRbase was used to check and unify the same miRNA with different names (http://www.mirbase.org/). Mean or median age, and male proportion of included studies were calculated using statistical software $\mathrm{R}$ (version 3.4.3, R Foundation, Vienna, Austria) if relevant information was not reported but raw data was available.

\section{Quality assessment of the included studies}

The two investigators independently assessed the quality of the included studies using QUADAS-2 (quality assessment tool for diagnostic accuracy studies) ${ }^{23}$ included in the Review Manager software (version 5.3.5, Cochrane Collaboration, Copenhagen, Denmark) package. $^{24}$ QUADAS-2 is used to evaluate the risk level of bias, which mainly consists of four components: (1) patient selection; (2) index test; (3) reference standard; and (4) flow and timing. The first three components also evaluate clinical applicability. Based on the answers to signaling questions included in each component, the risk level of bias is judged as "low", "high" or "unclear", and the clinical applicability is judged as "low", "high" or "unclear". Any disagreement, such as inconsistent answers 
to the questions, was settled by further discussion between the two investigators.

\section{Results}

\section{Literature search result}

The initial literature search yielded 903 articles according to the aforementioned retrieval strategy (Figure 1). After removing 294 duplicates, we looked through the titles and abstracts of the remaining 609 articles and further excluded 557 articles based on the exclusion criteria. The remaining 52 articles went through full-text reading, of which 23 articles were excluded for the following reasons: 13 using disease controls, three recruiting treated cases before specimen collection, and seven studies not reporting sensitivity, specificity or AUC values. Finally, 29 studies ${ }^{17-21,25-48}$ published between 2009 and 2018 were eligible for inclusion in

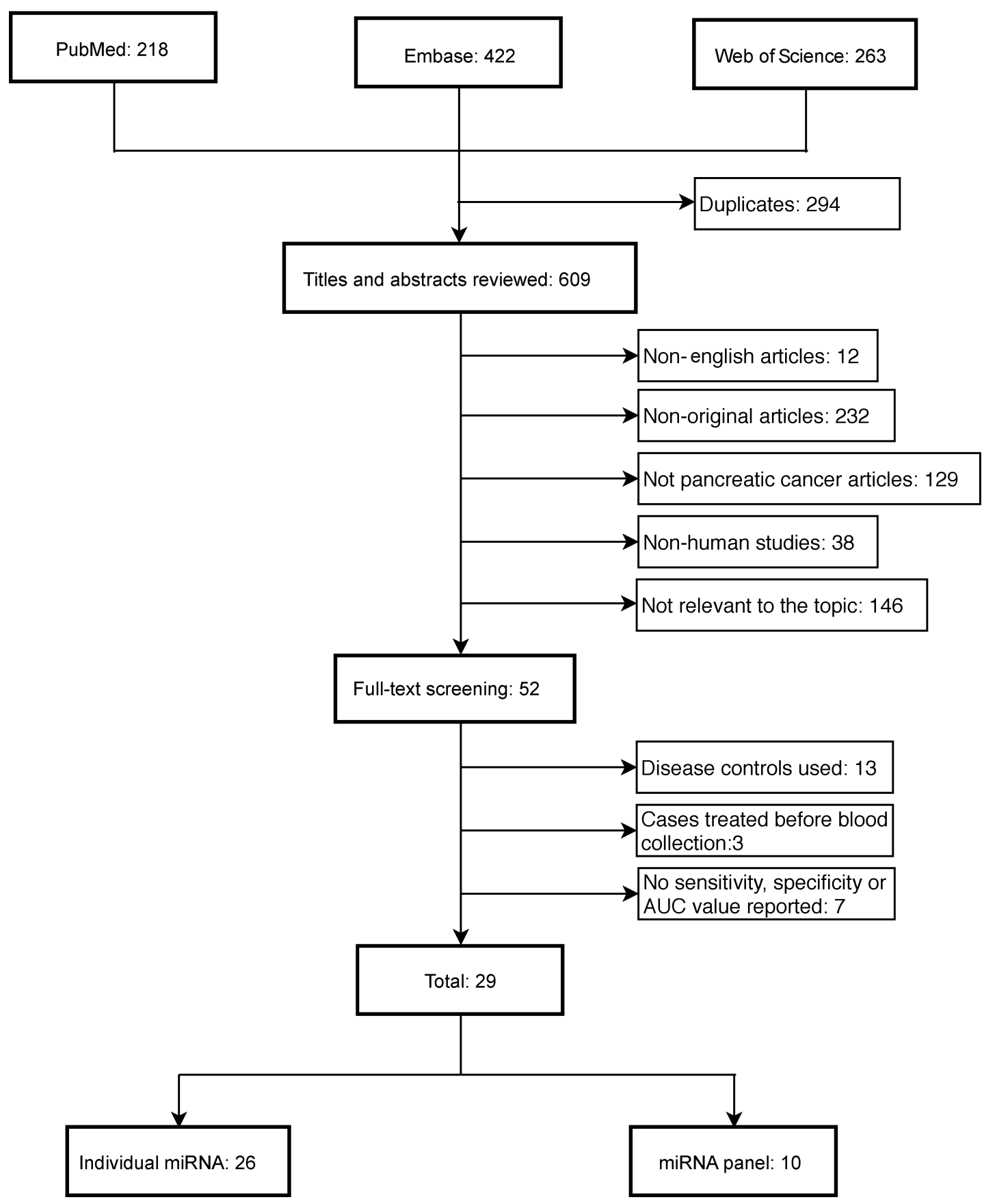

Figure I Overview of the literature search process (up to 28th of June 2018). 
this systematic review, and used to evaluate the diagnostic performance of circulating miRNAs for PC.

\section{Study quality and characteristics}

QUADAS-2 was carried out for the 29 included studies for quality assessment (Figures S1 and S2). High risk bias was found in seven studies (24\%) in the patient selection domain, and unclear risk bias was found in 13 studies $(45 \%)$ in the index test domain. For applicability concerns, 18 studies (62\%) displayed high concerns in patient selection domain, and 13 studies (45\%) displayed unclear concerns in the index test domain.

Of the 29 included studies, 18 were from East Asia, ${ }^{17,25-28,30-33,35,37-40,42,44,46,47}$ nine studies were from Europe and North America, ${ }^{18-21,34,41,43,45,48}$ one from Africa, ${ }^{29}$ and one from South America. ${ }^{36}$ The majority of the included studies were cross-sectional studies, and only two were nested case-control studies ${ }^{20,21}$ in which blood samples were taken before diagnosis. The median number (range) of included cases and controls was 56 (9-303) and 30 (6-600), respectively. Among the 29 included studies, four cross-sectional studies ${ }^{17,18,34,43}$ reported the diagnostic value of miRNAs for early stage (stage I and II) PC, and two nested case-control studies reported the predicted value of miRNAs for PC risk (Tables 1 and 2).

Fifteen studies analyzed plasma samples for miRNA, ${ }^{17,19-21,25,27-29,31,32,37-39,43,47} 12$ studies analyzed serum samples for miRNA, ${ }^{26,30,33-36,40-42,44-46}$ and two studies additionally analyzed exosomes samples for miRNA. ${ }^{17,18}$ Twenty-six studies reported 51 individual

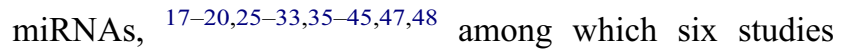
carried out external validation. ${ }^{28,31,32,37,43,45}$ Ten studies reported 13 miRNAs panels, ${ }^{20,21,34,36,41-43,46-48}$ of which three studies performed external validation (Tables 1 and 2). ${ }^{34,43,46}$ All included studies used quantitative realtime polymerase chain reaction (qRT-PCR) to detect miRNAs concentrations. The miRNAs were isolated by different extraction kits among the included studies; six studies $^{21,25,29,31,41,42}$ used miRNeasy Kit which has been proven to have a higher extraction efficiency. ${ }^{49}$ The normalization methods for the expression of miRNAs were not uniform, with cel-miR-39, U6 snRNA, miR-16 being the three most common reference standards for data normalization (Table S1).

\section{Diagnostic efficiency of miRNAs}

The 29 included studies reported a total number of 68 miRNAs with the diagnostic potential for PC, of which,
21 miRNAs were reported in more than two studies. The reported miRNA panels for PC diagnosis contained the number of miRNAs from 2 to 15 , with 10 miRNAs appearing in at least two panels (Table S2). Among studies with reported sensitivity and specificity, both exceeded $80 \%$ among 14 individual miRNAs (36\%) and 4 miRNAs panels (40\%) (Figure 2). Twenty-three individual miRNAs and four miRNA panels were externally validated, and diagnostic performance with $\geq 0.70$ AUC was observed in 18 miRNAs and all the four miRNA panels (Figure 3). MiR-21 is the most frequently reported miRNA (Table 3), whose sensitivity ranged from $46 \%$ to $100 \%$ (median sensitivity $78 \%$ ), the specificity ranged from $78 \%$ to $100 \%$ (median specificity $86 \%$ ), and the AUC values ranged from 0.62 to 1.00 (median AUC value $=0.83$ ). In the study by Lai et al., ${ }^{19}$ the sensitivity and specificity of miR-21, miR-10b, miR-30c, miR-181a, and miR-let7a in exosomes all reached $100 \%$ (Table 1). Several miRNAs panels showed excellent diagnostic performance for $\mathrm{PC} ;{ }^{41,46}$ the AUC values of 7-miRNA panel (miR-20a, $-21,-24,-25,-99 a,-185$, and -191) in Liu R's study and 2-miRNA panel (miR-196a and -196b) in Slater's study were 0.99 , and 1.00 , respectively (Table 2 ).

For early stage of PC, miR-20a, miR-21, miR-24, miR25, miR-99a, miR-185, and miR-191 were significantly dysregulated in serum samples of stage I (26 cases) and II (48 cases) PC patients compared to healthy controls in Liu R et al.'s study, ${ }^{46}$ with positive detection rates of $96 \%$ and $91.7 \%$, respectively. Johansen et al. ${ }^{34}$ evaluated the diagnostic efficiency of four miRNAs panels for stage I and II PC (Table 2), and the results showed AUC values of $0.87,0.86,0.77$, and 0.83 . Ganepola et al. ${ }^{43}$ investigated a 3-miRNA panel (miR-22, $-642 b$, and $-885-5 p$ ) for stage II PC and found the sensitivity, specificity, and AUC value were $91 \%, 91 \%$, and 0.97 , respectively. A nested casecontrol study by Duell et al. ${ }^{20}$ explored the risk prediction value of a 7-miRNA panel (miR-10a, $-10 \mathrm{~b},-21,-30 \mathrm{c}$, $-106 \mathrm{~b},-155$, and -212 ) in plasma for PC occurring in $\leq 5$ years, $\leq 8$ years, and $\leq 12$ years, and the results of which showed that the AUC values were 0.73, 0.70, and 0.69, respectively. More recently, Franklin et al. ${ }^{21}$ conducted a study which contained both prospective and cross-sectional (PC stage: I-II) parts. The prospective part indicated that the AUC values of a 15-miRNA panel (miR-106b, $-574,-34 \mathrm{a},-451 \mathrm{a},-130 \mathrm{~b},-26 \mathrm{a},-144,-423,-101,-122$, $-24,-22-5 p$, let-7d-3p, -197 , and $-885-5 p$ ) for predicting PC occurring in $\leq 5$ years, $5-10$ years, and $>10$ years were $0.60,0.55$, and 0.65 , respectively. The cross-sectional part 


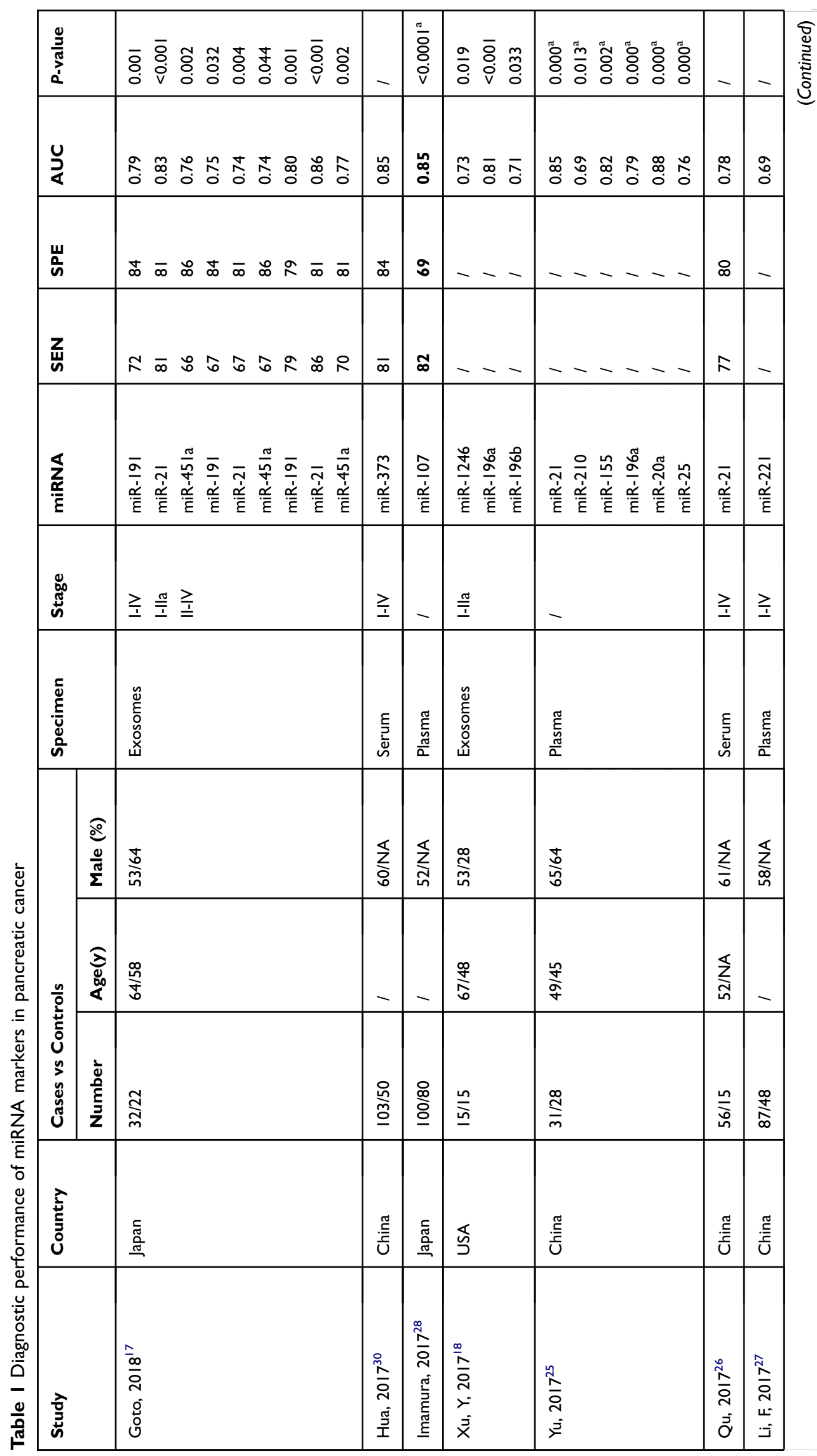




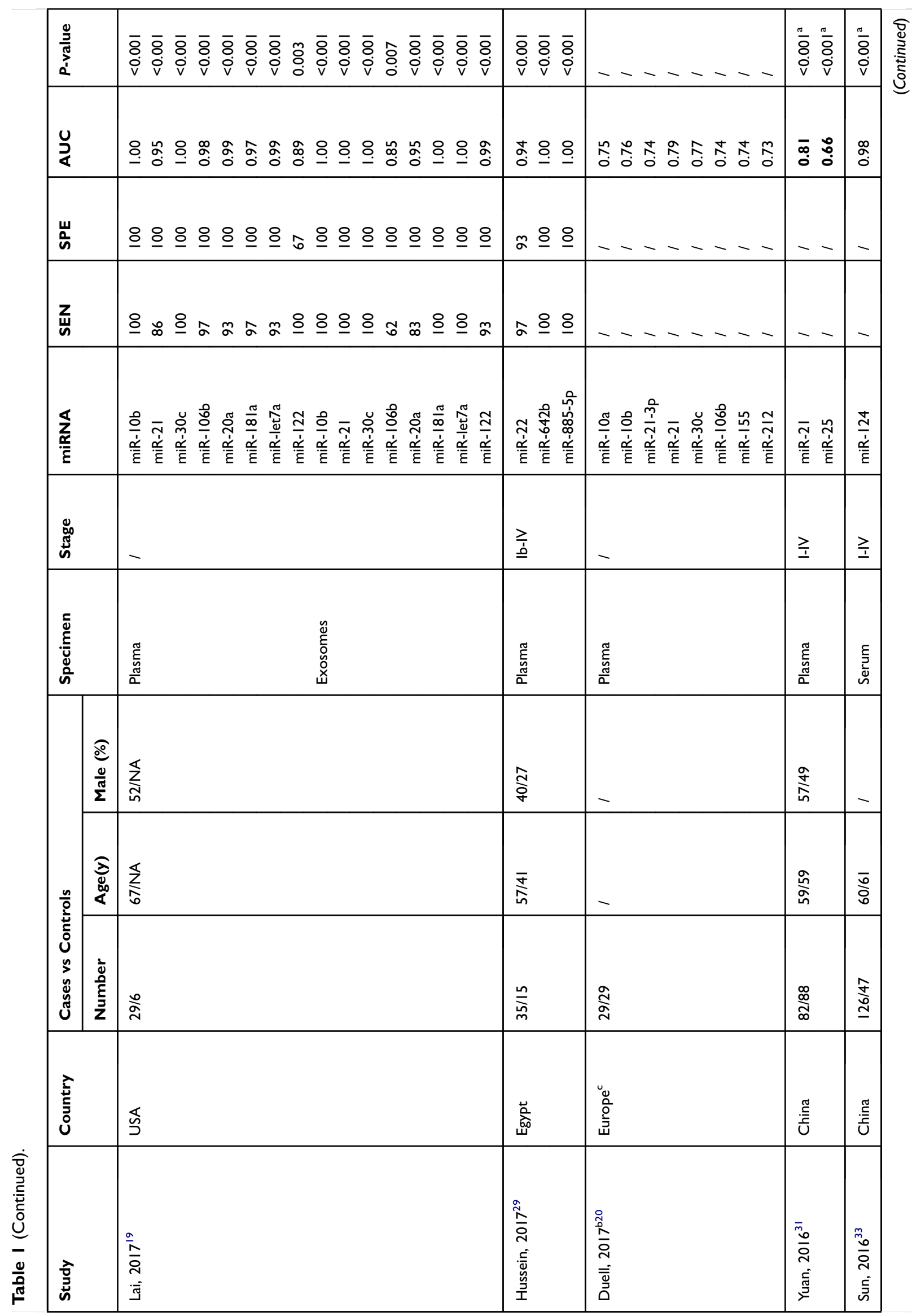




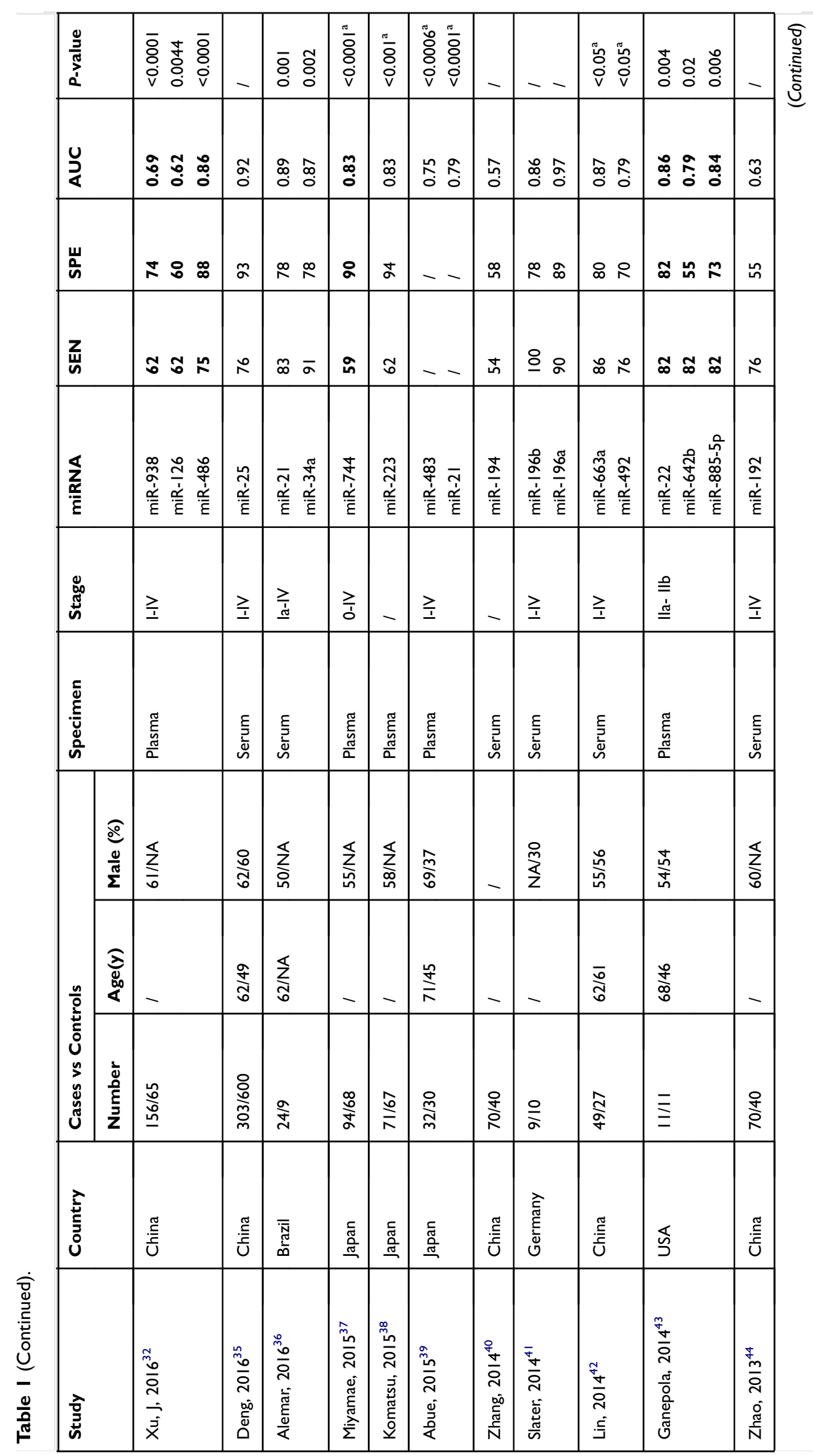




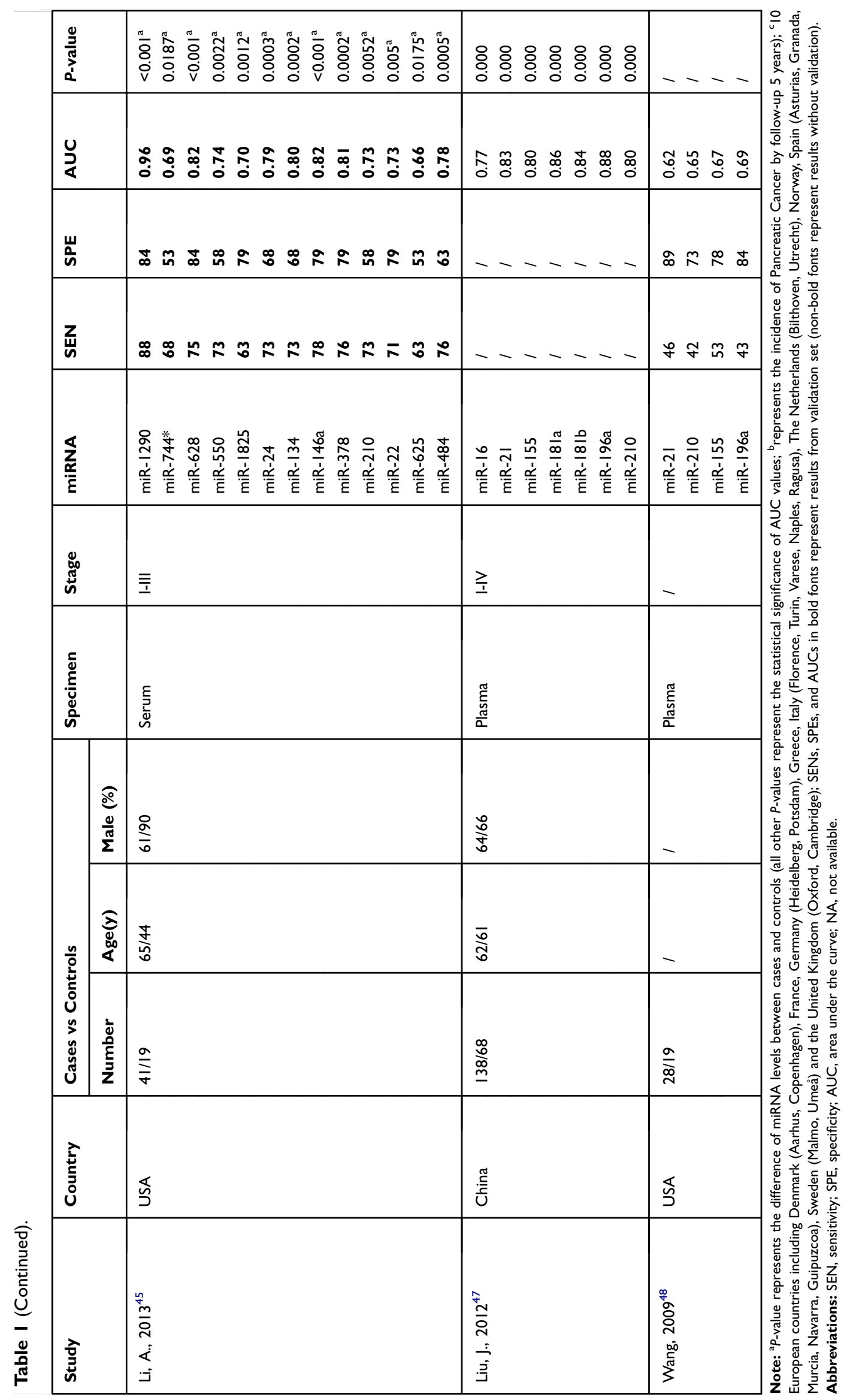




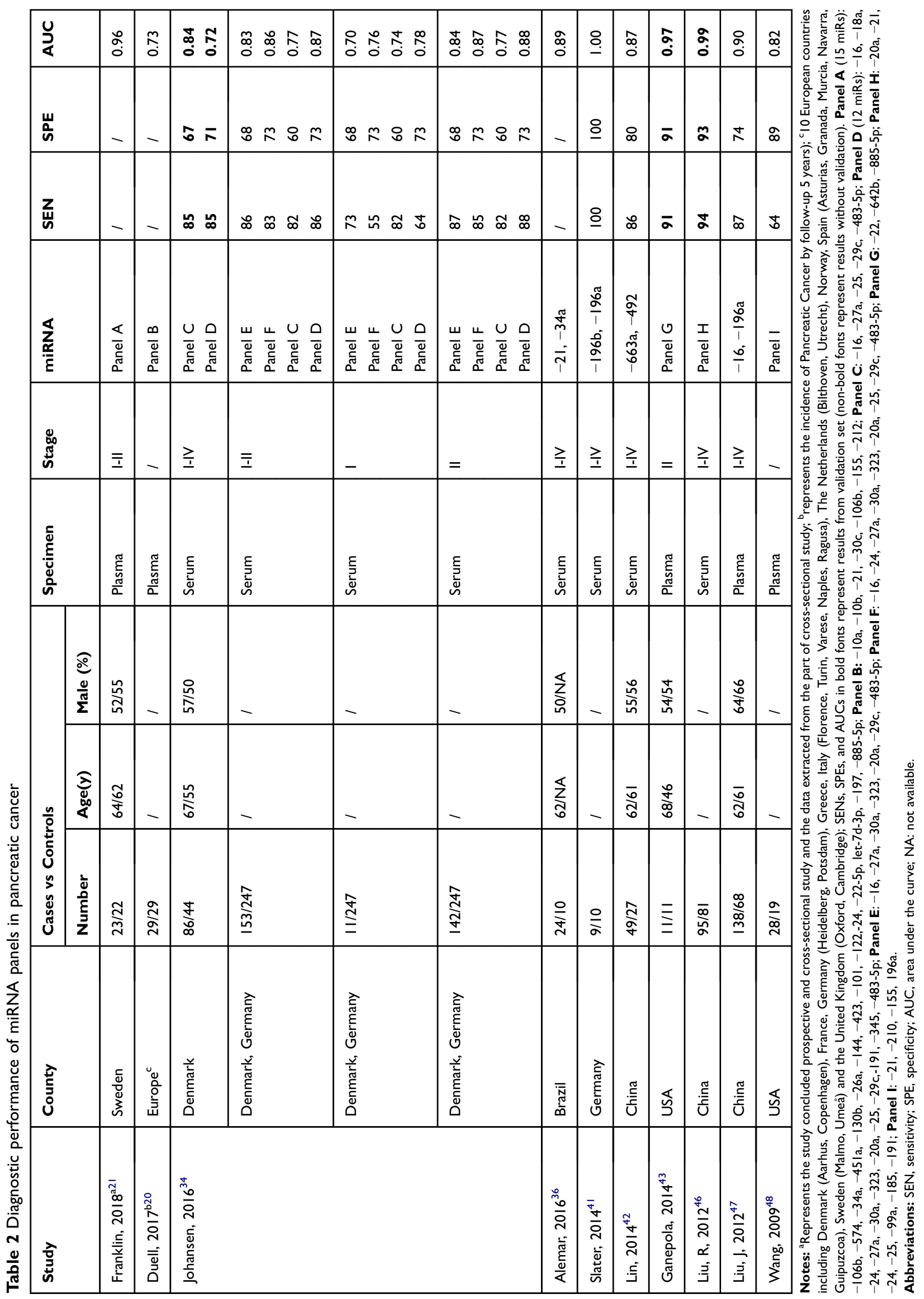




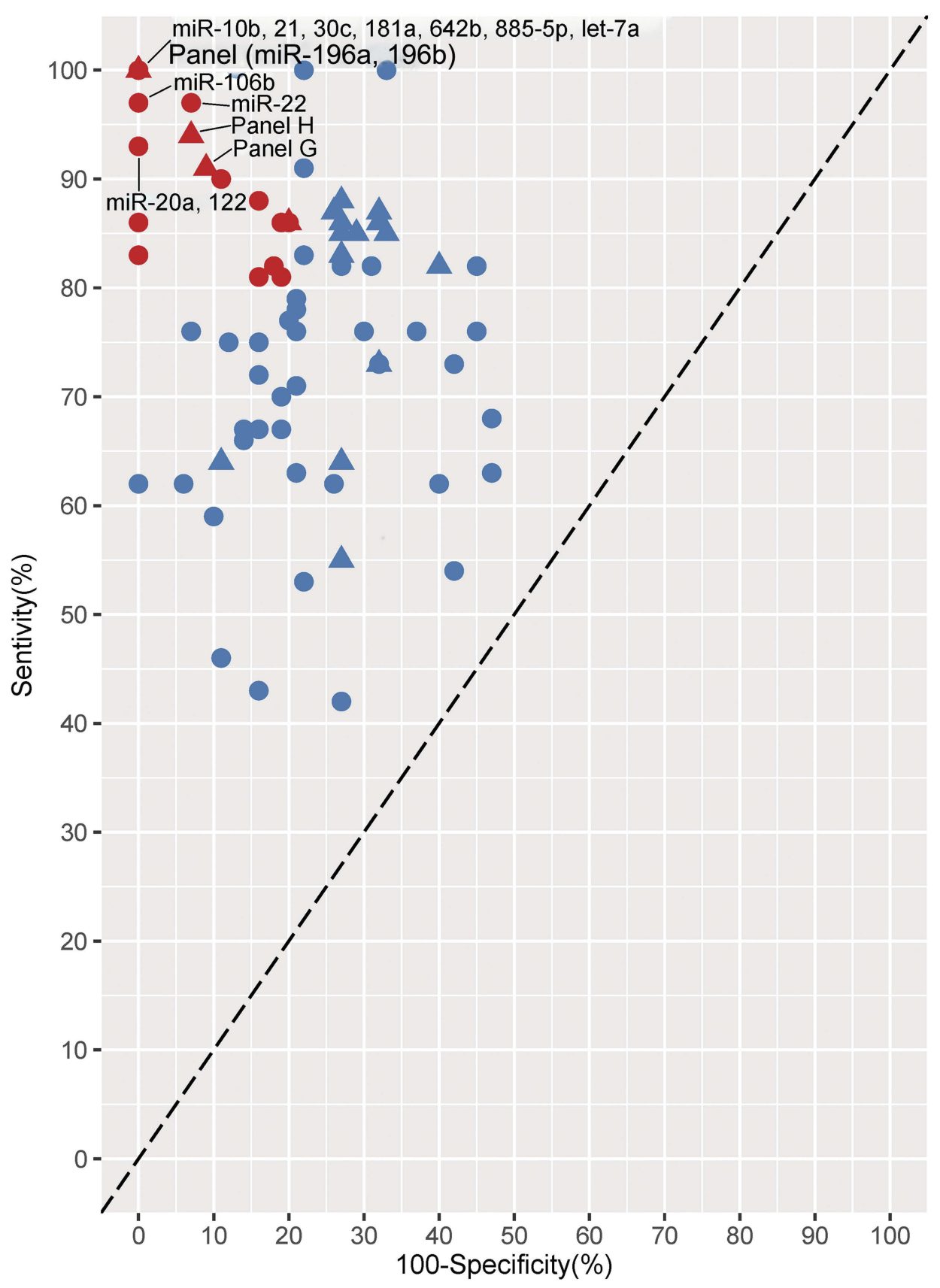

Figure 2 Graphical representation of sensitivity vs specificity of analyzed miRNAs. Sensitivity is plotted on the $y$-axis while on the $x$-axis the false-positive rate is presented (I00-Specificity). $O$ miRNA individual; $\triangle$ miRNA panel. Plots in red color represent miRNAs or miRNA panels with $\geq 80 \%$ sensitivity and $\geq 80$ specificity. (G): $-22,-642 b$, $-885-5 p ;(H):-20 a,-21,-24,-25,-99 a,-185,-191$.

reported that the AUC value of the above-mentioned miRNA panel for PC at diagnosis was 0.96 .

\section{Regulation direction of PC-related miRNA}

Of the 21 miRNAs reported more than twice, the dysregulation direction of most miRNAs was consistently upregulated, but the dysregulation direction of three miRNAs
(miR-106b, miR-122, and miR-451a) was inconsistent (Table 3). Of which, miR-106b was found to be upregulated in two studies ${ }^{19,20}$ and downregulated in one study; ${ }^{21}$ miR-122 and miR-451a were reported upregulated in one study ${ }^{17,21}$ and downregulated in another study, ${ }^{19,21}$ respectively. The inconsistent dysregulation direction of the above-mentioned miRNAs was not found to be significantly related to the specimen types or the stage of PC. ${ }^{17,19-21}$ 


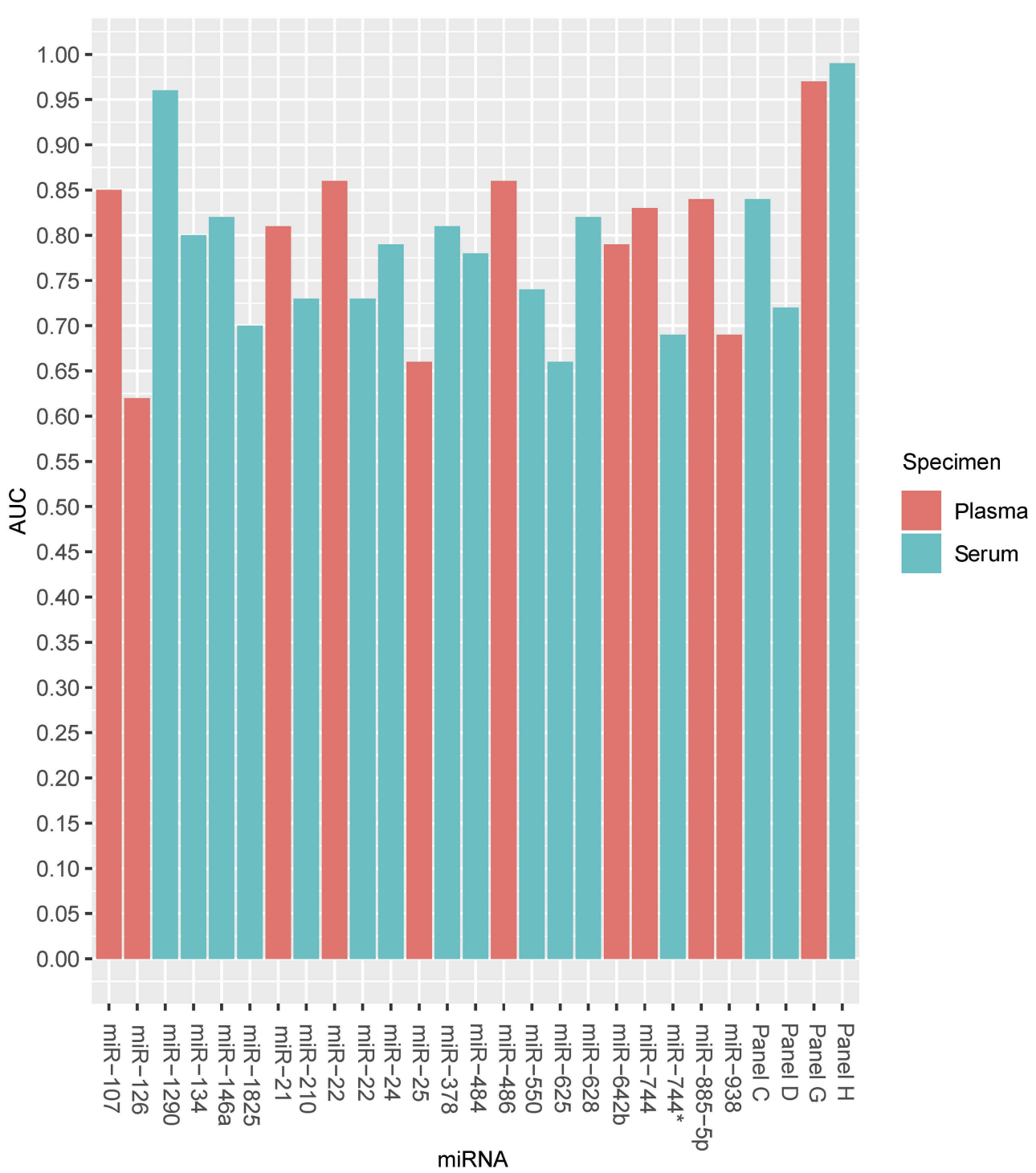

Figure 3 Graphical representation of diagnostic performance of the externally validated miRNAs and miRNA panels in PC. (C): $-16,-27 a,-25,-29 c,-483-5 p ;$ (D) (12 miRs): $-16,-18 a,-24,-27 a,-30 a,-323,-20 a,-25,-29 c,-191,-345,-483-5 p ;(\mathbf{G}):-22,-642 b,-885-5 p ;(\mathbf{H}):-20 a,-21,-24,-25,-99 a,-185,-191$.

Abbreviations: AUC, area under the curve; PC, pancreatic cancer.

\section{Discussion}

Our systematic review identified a total number of 68 miRNAs from 29 eligible studies evaluating the diagnostic performance of circulating miRNA for PC detection. Ten studies integrated individual miRNAs into miRNA panels (2-15 miRNAs for each panel) (Table 2). Two promising miRNA panels were discovered and verified in two cross-sectional studies, ${ }^{43,46}$ with AUC values all exceeding 0.95 . Only two studies ${ }^{17,34}$ conducted PC stage subgroup analysis for the diagnostic performance of miRNA. However, due to the lack of sufficient data, stage-specific miRNA for $\mathrm{PC}$ is still elusive.
Overall, circulating miRNAs present strong diagnostic value for PC with the sum of sensitivity and specificity of all reported miRNAs or miRNA panels being greater than one (Figure 2). Sensitivity and specificity both exceeded $80 \%$ in $36 \%$ of individual miRNAs and $40 \%$ of miRNA panels (Figure 2). Eleven miRNAs and three panels marked in Figure 2 showed even better diagnostic performance for PC with $\geq 90 \%$ sensitivity and $\geq 90 \%$ specificity. Ganepola et al. ${ }^{43}$ used a panel composed of miR-22, miR-642b-3p, and miR-885-5 in plasma for the diagnosis of stage II PC, and the AUC value reached 0.97. Another study by Liu R et al. ${ }^{46}$ used a panel consisting of miR-20a, miR-21, miR-24, miR-25, miR-99a, miR-185, and miR- 


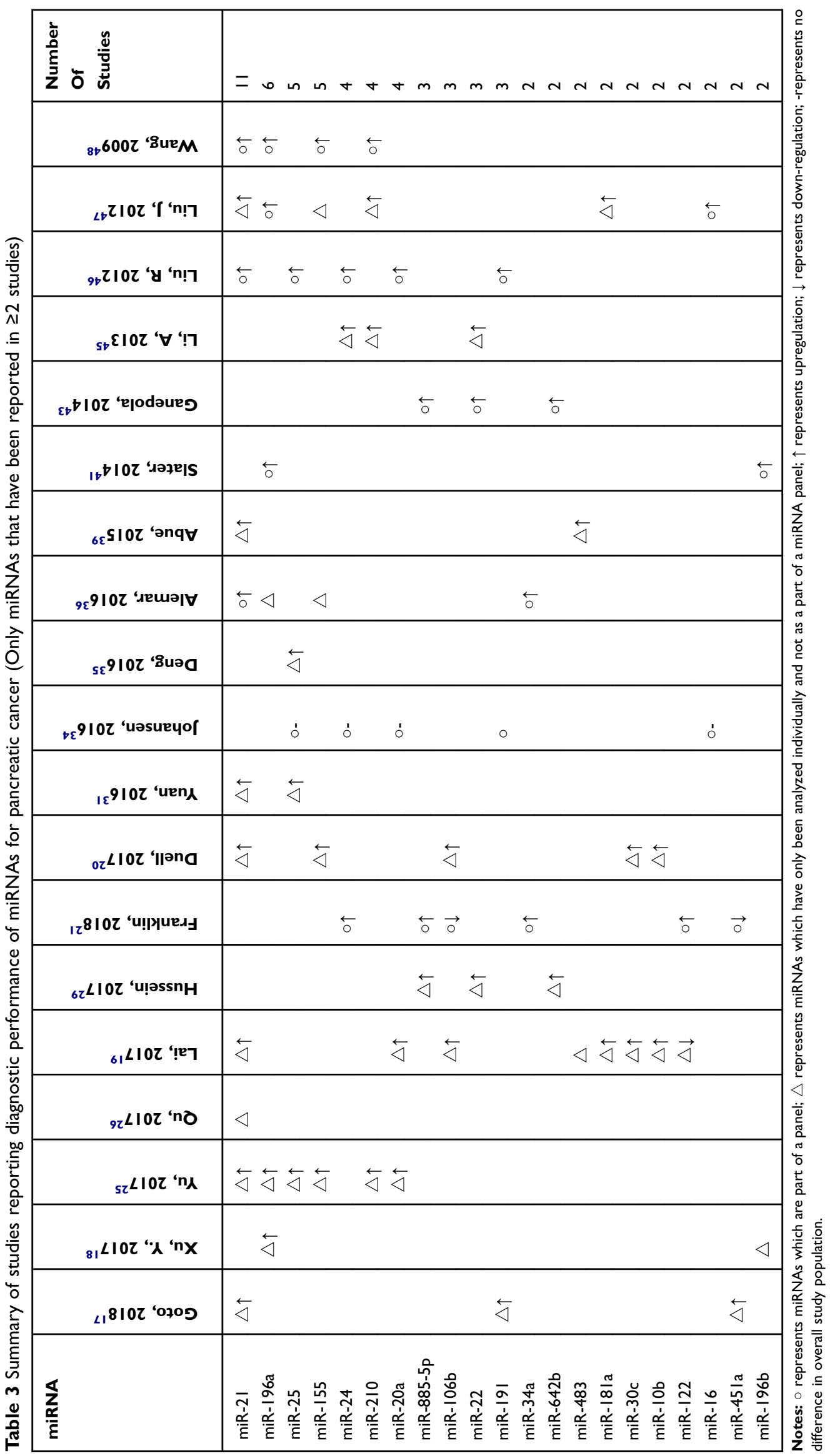


191 in serum for the diagnosis of stage I-IV PCs, and the AUC value reached 0.99. Moreover, the abovementioned results of the two studies have been externally verified (Figure 3). Two nested case-control studies ${ }^{20,21}$ showed that circulating miRNAs had certain predictive value for $\mathrm{PC}$ occurring in 5 years before diagnosis, but the performance in the PC-free participants is significantly lower compared to the participants being diagnosed with PC. The sample sizes were small in most included studies, and few studies conducted external validation, so the possibility of overestimation cannot be ruled out. Hence, further validation is still indispensable, especially based on large scale PC screening studies.

Some benign diseases and treatment measures may affect the identification of circulating miRNAs. Expression profiles of circulating miRNAs in chronic pancreatitis are different from that of $\mathrm{PC}$, but approximately $4 \%$ of chronic pancreatitis cases can develop PC within 20 years. ${ }^{50}$ Some studies ${ }^{51-53}$ have demonstrated that antineoplastic drugs and chemical regulators could regulate cell proliferation, apoptosis, and angiogenesis, all of which may impact miRNAs expression profiles. Therefore, in order to avoid the effect of disease and treatment on miRNA concentration, we only included healthy controls and PC cases sampled before any therapy. ${ }^{54-56}$

The overlap rates of PC-specific miRNAs are low in the current literature reports, and sometimes the regulation expression of the same miRNA in different studies was inconsistent. ${ }^{17,19-21}$ Consequently, screening of circulating miRNAs for PC detection requires attention. Circulating miRNAs concentration could be influenced by many factors, including: (1) population differences; ${ }^{57}$ (2) specimen types and volume ${ }^{58-60}$ (3) specimen preservation methods and time; ${ }^{61}$ (4) centrifugation steps; ${ }^{.5}$ (5) miRNA extraction kits; ${ }^{62}$ (6) normalization methods. ${ }^{58,63}$ The concentration of intracellular miRNAs is higher than that of extracellular miRNAs in blood, so hemolysis can cause a release of intracellular miRNAs, which may contaminate extracellular miRNAs, and affect the identification of PC-specific miRNAs. ${ }^{64-66}$ In addition, the blood samples in some studies ${ }^{18,19,34}$ were processed with only one-step centrifugation (Table S1), so the residual cell debris, containing high concentration miRNAs, may remain in the supernatant and contribute to the total miRNA content. At present, two-step centrifugation procedure is recommended, and the second step requires high-speed with a centrifugal force of $>15000 \mathrm{~g}$ to remove maximal cell debris to reduce their effect on the quantification of miRNAs in plasma and serum. ${ }^{58,59,67}$ The
miRNeasy kit is recommended as it has a higher miRNAs extraction efficiency compared to other kits, ${ }^{49}$ but not all studies have applied this extraction kit (Table S1). Different normalization methods could also influence the final quantitative results of circulating miRNAs and could even affect miRNAs expression regulation. ${ }^{58,68-70}$ Currently, qPCR quantitative standardization methods of miRNAs concentration are not uniform; cel-miR-39, U6 snRNA, and miR-16 are the most used standardization references in the included studies. The concentration of molecules used as the reference should be very stable among individuals, but there are still some references whose concentration varies between cancer cases and healthy controls, and result in a detection bias of miRNA concentration. ${ }^{58,69,71-74}$

Compared with other types of blood-based markers for PC detection, circulating miRNAs have the following advantages: (1) miRNAs are relatively stable and are insensitive to ribonuclease, acid or alkali environment, long-term room temperature preservation, and repeated freeze-thaw; ${ }^{68,75}$ (2) it can be repeatedly used as a noninvasive detection method; ${ }^{76,77}$ (3) it has certain predictive value for high PC risk population; ${ }^{20,21}$ and (4) the detection of miRNAs is relatively cheap. Other blood markers currently being used to diagnose PC - eg CA199, CA50, and CA242 - are often used to monitor the disease progression, ${ }^{78,79}$ but their diagnostic value is relatively low (whose sensitivity and specificity are generally lower than $81 \%$ and $80 \%$, respectively). ${ }^{80-82}$ In recent years, circulating tumor DNA (ctDNA), as a novel diagnostic marker for $\mathrm{PC}$, has also shown pretty good diagnostic value, the specificity of which can reach $92.6 \%$ or even exceed $99.9 \%$ in some studies, ${ }^{83,84}$ but the sensitivity is usually lower than $75 \%{ }^{84}$ In addition to identifying more circulating miRNAs for the formation of diagnostically superior miRNA panels for PC, future research should also focus on exploring possibilities of enhancing diagnostic power by combining miRNA makers with other novel laboratory markers, such as ctDNA markers, in a diagnostic model for early detection of PC.

\section{Conclusion}

This review indicates that circulating miRNAs hold the potential of being applied as diagnostic markers for PC. Future studies should pay more attention to the standardization of samples processing procedures and miRNA detection protocol. It is also necessary to verify these PC-specific miRNAs in 
larger scale screening studies, and examine the diagnostic efficiency of circulating miRNA for early stage PC.

\section{Disclosure}

The authors report no conflicts of interest in this work.

\section{References}

1. Siegel RL, Miller KD, Jemal A Cancer statistics, 2017. CA Cancer J Clin. 2017;67(1):7-30. doi:10.3322/caac.21387

2. Rahib L, Smith BD, Aizenberg R, Rosenzweig AB, Fleshman JM, Matrisian LM Projecting cancer incidence and deaths to 2030: the unexpected burden of thyroid, liver, and pancreas cancers in the United States. Cancer Res. 2014;74(11):2913-2921. doi:10.1158/ 0008-5472.CAN-14-0155

3. Kamisawa T, Wood LD, Itoi T, Takaori K Pancreatic cancer. Lancet. 2016;388(10039):73-85. doi:10.1016/S0140-6736(16)00141-0

4. Gillen S, Schuster T, Meyer Zum Buschenfelde C, Friess H, Kleeff J Preoperative/neoadjuvant therapy in pancreatic cancer: a systematic review and meta-analysis of response and resection percentages. PLoS Med. 2010;7(4):e1000267. doi:10.1371/journal. pmed. 1000267

5. Prokesch RW, Chow LC, Beaulieu CF, Bammer R, Jeffrey RB Jr. Isoattenuating pancreatic adenocarcinoma at multi-detector row $\mathrm{CT}$ : secondary signs. Radiology. 2002;224(3):764-768. doi:10.1148/ radiol.2243011284

6. To'o KJ, Raman SS, Yu NC, et al. Pancreatic and peripancreatic diseases mimicking primary pancreatic neoplasia. Radiographics. 2005;25(4):949-965. doi:10.1148/rg.254045167

7. Chu LC, Goggins MG, Fishman EK Diagnosis and detection of pancreatic cancer. Cancer J. 2017;23(6):333-342. doi:10.1097/ PPO.0000000000000290

8. Chen FM, Ni JM, Zhang ZY, Zhang L, Li B, Jiang CJ Presurgical evaluation of pancreatic cancer: a comprehensive imaging comparison of CT versus MRI. AJR Am J Roentgenol. 2016;206(3):526-535. doi:10.2214/AJR.15.15236

9. Wiersema MJ, Vilmann P, Giovannini M, Chang KJ, Wiersema LM Endosonography-guided fine-needle aspiration biopsy: diagnostic accuracy and complication assessment. Gastroenterology. 1997;112 (4):1087-1095. doi:10.1016/s0016-5085(97)70164-1

10. Satake K, Kanazawa G, Kho I, Chung Y, Umeyama K Evaluation of serum pancreatic enzymes, carbohydrate antigen 19-9, and carcinoembryonic antigen in various pancreatic diseases. $A m \quad J$ Gastroenterol. 1985;80(8):630-636.

11. Ballehaninna UK, Chamberlain RS Biomarkers for pancreatic cancer: promising new markers and options beyond CA 19-9. Tumour Biol. 2013;34(6):3279-3292. doi:10.1007/s13277-013-1033-3

12. Wang J, Wang X, Yu F, et al. Combined detection of preoperative serum CEA, CA19-9 and CA242 improve prognostic prediction of surgically treated colorectal cancer patients. Int J Clin Exp Pathol. 2015;8(11):14853-14863.

13. Takezako Y, Okusaka T, Ueno H, Ikeda M, Morizane C, Najima M [Tumor markers for pancreatic and biliary tract cancer]. Gan to Kagaku Ryoho Cancer Chemother. 2004;31(9):1443-1446.

14. Iorio MV, Croce CM MicroRNA dysregulation in cancer: diagnostics, monitoring and therapeutics. A comprehensive review. EMBO Mol Med. 2017;9(6):852. doi:10.15252/emmm.201707779

15. Weber JA, Baxter DH, Zhang S, et al. The microRNA spectrum in 12 body fluids. Clin Chem. 2010;56(11):1733-1741. doi:10.1373/ clinchem.2010.147405

16. Lagos-Quintana M, Rauhut R, Lendeckel W, Tuschl T Identification of novel genes coding for small expressed RNAs. Science. 2001;294 (5543):853-858. doi:10.1126/science.1064921
17. Goto T, Fujiya M, Konishi H, et al. An elevated expression of serum exosomal microRNA-191, - 21, -451a of pancreatic neoplasm is considered to be efficient diagnostic marker. BMC Cancer. 2018;18 (1):116. doi:10.1186/s12885-018-4242-8

18. Xu YF, Hannafon BN, Zhao YD, Postier RG, Ding WQ Plasma exosome miR-196a and miR-1246 are potential indicators of localized pancreatic cancer. Oncotarget. 2017;8(44):77028-77040. doi:10.18632/oncotarget.20332

19. Lai X, Wang M, McElyea SD, Sherman S, House M, Korc M A microRNA signature in circulating exosomes is superior to exosomal glypican-1 levels for diagnosing pancreatic cancer. Cancer Lett. 2017;393:86-93. doi:10.1016/j.canlet.2017.02.019

20. Duell EJ, Lujan-Barroso L, Sala N, et al. Plasma microRNAs as biomarkers of pancreatic cancer risk in a prospective cohort study. Int J Cancer. 2017. doi:10.1002/ijc.30790

21. Franklin O, Jonsson $\mathrm{P}$, Billing $\mathrm{O}$, et al. Plasma Micro-RNA Alterations Appear Late in Pancreatic Cancer. Annals of Surgery. 2018;267(4):775-781. doi:10.1097/sla.0000000000002124

22. Moher D, Liberati A, Tetzlaff J, Altman DG, Group P Preferred reporting items for systematic reviews and meta-analyses: the PRISMA statement. J Clin Epidemiol. 2009;62(10):1006-1012. doi:10.1016/j.jclinepi.2009.06.005

23. Whiting PF, Rutjes AWS, Westwood ME, et al. QUADAS-2: a revised tool for the quality assessment of diagnostic accuracy studies. Ann Intern Med. 2011;155(8):529-U104. doi:10.7326/0003-4819155-8-201110180-00009

24. Bae JM An overview of systematic reviews of diagnostic tests accuracy. Epidemiol Health. 2014;36:e2014016. doi:10.4178/epih/e2014016

25. Yu Q, Xu CQ, Yuan W, et al. Evaluation of plasma MicroRNAs as diagnostic and prognostic biomarkers in pancreatic adenocarcinoma: miR-196a and miR-210 could be negative and positive prognostic markers, respectively. Biomed Res Int. 2017. doi:10.1155/2017/6495867

26. Qu K, Zhang X, Lin T, et al. Circulating miRNA-21-5p as a diagnostic biomarker for pancreatic cancer: evidence from comprehensive miRNA expression profiling analysis and clinical validation. Sci Rep. 2017;7(1):1692. doi:10.1038/s41598-017-01904-z

27. Li F, Xu JW, Wang L, et al. MicroRNA-221-3p is up-regulated and serves as a potential biomarker in pancreatic cancer. Artif Cells Nanomed Biotechnol. 2017;46(3):482-487. doi:10.1080/ 21691401.2017.1315429

28. Imamura T, Komatsu S, Ichikawa D, et al. Depleted tumor suppressor miR-107 in plasma relates to tumor progression and is a novel therapeutic target in pancreatic cancer. Sci Rep. 2017;7(1):5708. doi:10.1038/s41598-017-06137-8

29. Hussein NA, El Kholy ZA, Anwar MM, Ahmad MA, Ahmad SM Plasma miR-22-3p, miR-642b-3p and miR-885-5p as diagnostic biomarkers for pancreatic cancer. J Cancer Res Clin Oncol. 2017;143 (1):83-93. doi:10.1007/s00432-016-2248-7

30. Hua Y, Chen H, Wang L, et al. Low serum miR-373 predicts poor prognosis in patients with pancreatic cancer. Cancer Biomarkers. 2017;20(1):95-100. doi:10.3233/CBM-170231

31. Yuan W, Tang W, Xie Y, et al. New combined microRNA and protein plasmatic biomarker panel for pancreatic cancer. Oncotarget. 2016;7 (48):80033-80045. doi:10.18632/oncotarget.12406

32. Xu J, Cao Z, Liu W, et al. Plasma miRNAs effectively distinguish patients with pancreatic cancer from controls a multicenter study. Ann Surg. 2016;263(6):1173-1179.

33. Sun B, Liu X, Gao Y, Li L, Dong Z Downregulation of miR-124 predicts poor prognosis in pancreatic ductal adenocarcinoma patients. Br J Biomed Sci. 2016;73(4):152-157. doi:10.1080/09674845.2016.1220706

34. Johansen JS, Calatayud D, Albieri V, et al. The potential diagnostic value of serum microRNA signature in patients with pancreatic cancer. Int J Cancer. 2016;139(10):2312-2324. doi:10.1002/ijc.30291

35. Deng T, Yuan YZ, Zhang CN, et al. Identification of circulating MiR25 as a potential biomarker for pancreatic cancer diagnosis. Cell Physiol Biochem. 2016;39(5):1716-1722. doi:10.1159/000447872 
36. Alemar B, Izetti P, Gregorio C, et al. miRNA-21 and miRNA-34a are potential minimally invasive biomarkers for the diagnosis of pancreatic ductal adenocarcinoma. Pancreas. 2016;45(1):84-92. doi:10.109 7/MPA.0000000000000383

37. Miyamae M, Komatsu S, Ichikawa D, et al. Plasma microRNA profiles: identification of miR-744 as a novel diagnostic and prognostic biomarker in pancreatic cancer. $B r J$ Cancer. 2015;113 (10):1467-1476. doi:10.1038/bjc.2015.366

38. Komatsu S, Ichikawa D, Miyamae M, et al. Malignant potential in pancreatic neoplasm: new insights provided by circulating mir-223 in plasma. J Am Coll Surg. 2015;221(4):e20-e21. doi:10.1016/j. jamcollsurg.2015.08.351

39. Abue M, Yokoyama M, Shibuya R, et al. Circulating miR-483-3p and miR-21 is highly expressed in plasma of pancreatic cancer. Int $J$ Oncol. 2015;46(2):539-547. doi:10.3892/ijo.2014.2743

40. Zhang J, Zhao CY, Zhang SH, et al. Upregulation of miR-194 contributes to tumor growth and progression in pancreatic ductal adenocarcinoma. Oncol Rep. 2014;31(3):1157-1164. doi:10.3892/or.2013.2960

41. Slater EP, Strauch K, Rospleszcz S, et al. MicroRNA-196a and-196b as potential biomarkers for the early detection of familial pancreatic cancer. Transl Oncol. 2014;7(4):464-471. doi:10.1016/j. tranon.2014.05.007

42. Lin MS, Chen WC, Huang JX, Gao HJ, Sheng HH Aberrant expression of microRNAs in serum may identify individuals with pancreatic cancer. Int J Clin Exp Med. 2014;7(12):5226-5234.

43. Ganepola GA, Rutledge JR, Suman P, Yiengpruksawan A, Chang DH Novel blood-based microRNA biomarker panel for early diagnosis of pancreatic cancer. World J Gastrointest Oncol. 2014;6(1):22-33. doi:10.4251/wjgo.v6.i1.22

44. Zhao C, Zhang J, Zhang S, et al. Diagnostic and biological significance of microRNA-192 in pancreatic ductal adenocarcinoma. Oncol Rep. 2013;30(1):276-284. doi:10.3892/or.2013.2420

45. Li A, Yu J, Kim H, et al. MicroRNA array analysis finds elevated serum miR-1290 accurately distinguishes patients with low-stage pancreatic cancer from healthy and disease controls. Clin Cancer Res. 2013;19(13):3600-3610. doi:10.1158/1078-0432.CCR-123092

46. Liu R, Chen X, Du Y, et al. Serum microRNA expression profile as a biomarker in the diagnosis and prognosis of pancreatic cancer. Clin Chem. 2012;58(3):610-618. doi:10.1373/clinchem.2011.172767

47. Liu J, Gao J, Du Y, et al. Combination of plasma microRNAs with serum CA19-9 for early detection of pancreatic cancer. Int J Cancer. 2012;131(3):683-691. doi:10.1002/ijc.26422

48. Wang J, Chen J, Chang P, et al. MicroRNAs in plasma of pancreatic ductal adenocarcinoma patients as novel blood-based biomarkers of disease. Cancer Prev Res. 2009;2(9):807-813. doi:10.1158/19406207.CAPR-09-0094

49. Doleshal M, Magotra AA, Choudhury B, Cannon BD, Labourier E, Szafranska AE Evaluation and validation of total RNA extraction methods for microRNA expression analyses in formalin-fixed, paraffin-embedded tissues. J Mol Diagn. 2008;10(3):203-211. doi:10.2353/jmoldx.2008.070153

50. Steer ML, Waxman I, Freedman S Chronic pancreatitis. $N$ Engl J Med. 1995;332(22):1482-1490. doi:10.1056/NEJM199506013322206

51. Blower PE, Chung JH, Verducci JS, et al. MicroRNAs modulate the chemosensitivity of tumor cells. Mol Cancer Ther. 2008;7(1):1-9. doi:10.1158/1535-7163.MCT-07-0573

52. Scott GK, Mattie MD, Berger CE, Benz SC, Benz CC Rapid alteration of microRNA levels by histone deacetylase inhibition. Cancer Res. 2006;66(3):1277-1281. doi:10.1158/0008-5472.CAN-05-3632

53. Liu H, D'Andrade P, Fulmer-Smentek S, et al. mRNA and microRNA expression profiles of the NCI-60 integrated with drug activities. Mol Cancer Ther. 2010;9(5):1080-1091. doi:10.1158/ 1535-7163.MCT-09-0965
54. Morimura R, Komatsu S, Ichikawa D, et al. Novel diagnostic value of circulating miR-18a in plasma of patients with pancreatic cancer. Br J Cancer. 2011;105(11):1733-1740. doi:10.1038/bjc.2011.453

55. Kojima M, Sudo H, Kawauchi J, et al. MicroRNA markers for the diagnosis of pancreatic and biliary-tract cancers. PLoS One. 2015;10 (2):e0118220. doi:10.1371/journal.pone.0118220

56. Kawaguchi T, Komatsu S, Ichikawa D, et al. Clinical impact of circulating miR-221 in plasma of patients with pancreatic cancer. Br J Cancer. 2013;108(2):361-369. doi:10.1038/bjc.2012.546

57. Becker N, Lockwood CM Pre-analytical variables in miRNA analysis. Clin Biochem. 2013; 46 (10-11): 861-868. doi:10.1016/j. clinbiochem.2013.02.015

58. McDonald JS, Milosevic D, Reddi HV, Grebe SK, AlgecirasSchimnich A Analysis of circulating microRNA: preanalytical and analytical challenges. Clin Chem. 2011;57(6):833-840. doi:10.1373/ clinchem.2010.157198

59. Page K, Guttery DS, Zahra N, et al. Influence of plasma processing on recovery and analysis of circulating nucleic acids. PLoS One. 2013;8(10):e77963. doi:10.1371/journal.pone.0077963

60. Kim DJ, Linnstaedt S, Palma J, et al. Plasma components affect accuracy of circulating cancer-related microRNA quantitation. $J$ Mol Diagn. 2012;14(1):71-80. doi:10.1016/j.jmoldx.2011.09.002

61. Gilad S, Meiri E, Yogev Y, et al. Serum microRNAs are promising novel biomarkers. PLoS One. 2008;3(9):e3148. doi:10.1371/journal. pone.0003148

62. Li Y, Kowdley KV Method for microRNA isolation from clinical serum samples. Anal Biochem. 2012;431(1):69-75. doi:10.1016/j. ab.2012.09.007

63. Kroh EM, Parkin RK, Mitchell PS, Tewari M Analysis of circulating microRNA biomarkers in plasma and serum using quantitative reverse transcription-PCR (qRT-PCR). Methods. 2010;50(4):298301. doi:10.1016/j.ymeth.2010.01.032

64. Petriv OI, Kuchenbauer F, Delaney AD, et al. Comprehensive microRNA expression profiling of the hematopoietic hierarchy. Proc Natl Acad Sci $U$ S A. 2010;107(35):15443-15448. doi:10.1073/pnas.1009320107

65. Kannan M, Atreya C Differential profiling of human red blood cells during storage for 52 selected microRNAs. Transfusion. 2010;50 (7):1581-1588. doi:10.1111/j.1537-2995.2010.02585.x

66. Rossi RL, Rossetti G, Wenandy L, et al. Distinct microRNA signatures in human lymphocyte subsets and enforcement of the naive state in CD4+ T cells by the microRNA miR-125b. Nat Immunol. 2011;12(8):796-803. doi:10.1038/ni.2057

67. Duttagupta R, Jiang R, Gollub J, Getts RC, Jones KW Impact of cellular miRNAs on circulating miRNA biomarker signatures. PLoS One. 2011;6(6):e20769. doi:10.1371/journal.pone.0020769

68. Mitchell PS, Parkin RK, Kroh EM, et al. Circulating microRNAs as stable blood-based markers for cancer detection. Proc Natl Acad Sci USA. 2008;105(30):10513-10518. doi:10.1073/pnas.0804549105

69. Xiang M, Zeng Y, Yang R, et al. U6 is not a suitable endogenous control for the quantification of circulating microRNAs. Biochem Biophys Res Commun. 2014;454(1):210-214. doi:10.1016/j.bbrc.2014.10.064

70. Qi R, Weiland M, Gao XH, Zhou L, Mi QS Identification of endogenous normalizers for serum microRNAs by microarray profiling: U6 small nuclear RNA is not a reliable normalizer. Hepatology. 2012;55(5):16401642; author reply 1642-1643. doi:10.1002/hep. 25558

71. Fan L, Qi H, Teng J, et al. Identification of serum miRNAs by nanoquantum dots microarray as diagnostic biomarkers for early detection of non-small cell lung cancer. Tumour Biol. 2016;37(6):7777-7784. doi:10.1007/s13277-015-4608-3

72. Wang Y, Gu J, Roth JA, et al. Pathway-based serum microRNA profiling and survival in patients with advanced stage non-small cell lung cancer. Cancer Res. 2013;73(15):4801-4809. doi:10.1158/ 0008-5472.CAN-12-3273 
73. Diaz-Garcia CV, Agudo-Lopez A, Perez C, et al. DICER1, DROSHA and miRNAs in patients with non-small cell lung cancer: implications for outcomes and histologic classification. Carcinogenesis. 2013;34 (5):1031-1038. doi:10.1093/carcin/bgt022

74. Appaiah HN, Goswami CP, Mina LA, et al. Persistent upregulation of U6: SNORD44 small RNA ratio in the serum of breast cancer patients. Breast Cancer Research. 2011;13(5):R86. doi:10.1186/ bcr2943

75. Grasedieck S, Scholer N, Bommer M, et al. Impact of serum storage conditions on microRNA stability. Leukemia. 2012;26(11):24142416. doi:10.1038/leu.2012.106

76. Chen X, Ba Y, Ma L, et al. Characterization of microRNAs in serum: a novel class of biomarkers for diagnosis of cancer and other diseases. Cell Res. 2008;18(10):997-1006. doi:10.1038/cr.2008.282

77. Chevillet JR, Lee I, Briggs HA, He Y, Wang K Issues and prospects of microRNA-based biomarkers in blood and other body fluids. Molecules. 2014;19(5):6080-6105. doi:10.3390/molecules19056080

78. Chen Y, Gao SG, Chen JM, et al. Serum CA242, CA199, CA125, CEA, and TSGF are biomarkers for the efficacy and prognosis of cryoablation in pancreatic cancer patients. Cell Biochem Biophys. 2015;71(3):1287-1291. doi:10.1007/s12013-014-0345-2
79. Zhou G, Niu L, Chiu D, He L, Xu K Changes in the expression of serum markers CA242, CA199, CA125, CEA, TNF-alpha and TSGF after cryosurgery in pancreatic cancer patients. Biotechnol Lett. 2012;34(7):1235-1241. doi:10.1007/s10529-012-0908-5

80. Lei XF, Jia SZ, Ye J, et al. Application values of detection of serum CA199, CA242 and CA50 in the diagnosis of pancreatic cancer. $J$ Biol Regul Homeost Agents. 2017;31(2):383-388.

81. Ni XG, Bai XF, Mao YL, et al. The clinical value of serum CEA, CA19-9, and CA242 in the diagnosis and prognosis of pancreatic cancer. Eur J Surg Oncol. 2005;31(2):164-169. doi:10.1016/j. ejso.2004.09.007

82. Zhang Y, Yang J, Li H, Wu Y, Zhang H, Chen W Tumor markers CA19-9, CA242 and CEA in the diagnosis of pancreatic cancer: a meta-analysis. Int J Clin Exp Med. 2015;8(7):11683-11691.

83. Sausen M, Phallen J, Adleff V, et al. Clinical implications of genomic alterations in the tumour and circulation of pancreatic cancer patients. Nat Commun. 2015;6:7686. doi:10.1038/ncomms8686

84. Allenson K, Castillo J, San Lucas FA, et al. High prevalence of mutant KRAS in circulating exosome-derived DNA from earlystage pancreatic cancer patients. Ann Oncol. 2017;28(4):741-747. doi:10.1093/annonc/mdx004 


\section{Supplementary materials}

Table SI Protocols of blood miRNA detection

\begin{tabular}{|c|c|c|c|c|}
\hline Ref & Specimen & Centrifugation & Extraction & Normalization \\
\hline Yu, 2017' & Plasma & $1200 \mathrm{~g}$ for $10 \mathrm{~min}, 12000 \mathrm{~g}$ for $10 \mathrm{~min}$ & $\begin{array}{l}\text { miRNeasy Serum/Plasma } \\
\text { Kit }\end{array}$ & $\begin{array}{l}\text { miRNeasy Serum/Plasma Spike- } \\
\text { In Control (miR-39) }\end{array}$ \\
\hline $\mathrm{Qu}, 2017^{2}$ & Plasma & NA & TRIzol LS Reagent & cel-miR-39 \\
\hline $\mathrm{Li}, 2017^{3}$ & Plasma & $3500 \mathrm{rpm}$ for $10 \mathrm{~min}$ & mirVana PARIS Kit & U6 snRNA \\
\hline \multirow[t]{2}{*}{ Lai, $2017^{4}$} & Plasma & $1000 \mathrm{~g}$ for $30 \mathrm{~min}$ & NA & NA \\
\hline & Exosomes & $\begin{array}{l}1000 \mathrm{~g} \text { for } 30 \mathrm{~min}, 10000 \mathrm{~g} \text { for } 30 \mathrm{~min} \text {, (thaw) } \\
10000 \mathrm{~g} \text { for } 30 \mathrm{~min}, 11000 \mathrm{~g} \text { for } 2 \mathrm{~h}\end{array}$ & $\begin{array}{l}\text { Trizol-LS and Direct-zol } \\
\text { RNA MiniPrep kit }\end{array}$ & miR-425-5p \\
\hline Hussein, $2017^{5}$ & Plasma & NA & $\begin{array}{l}\text { miRNeasy serum/plasma } \\
\text { Kit }\end{array}$ & miR-3I96 \\
\hline Franklin, $2017^{6}$ & Plasma & NA & $\begin{array}{l}\text { miRNeasy Serum/Plasma } \\
\text { Kit }\end{array}$ & NA \\
\hline Duell, $2017^{7}$ & Plasma & NA & $\begin{array}{l}\text { Trizol-LS and Direct-zol } \\
\text { RNA MiniPrep kit }\end{array}$ & miR-425-5p \\
\hline Yuan, $2016^{8}$ & Plasma & NA & $\begin{array}{l}\text { miRNeasy Serum/Plasma } \\
\text { Kit }\end{array}$ & cel-miR-39 \\
\hline $\mathrm{Xu}, 2016^{9}$ & Plasma & $3000 \mathrm{rpm}$ for $10 \mathrm{~min}$ & mirVana PARIS kit & U6 snRNA \\
\hline Sun, $2016^{10}$ & Serum & NA & NA & U6 snRNA \\
\hline Johansen, 2016"1 & Serum & $2500 \mathrm{~g}$ for $10 \mathrm{~min}$ & TRI Reagent BD & NA \\
\hline Deng, $2016^{12}$ & Serum & NA & NA & $\begin{array}{l}\text { normalized to the serum } \\
\text { volume }\end{array}$ \\
\hline Alemar, $2016^{13}$ & Serum & $1500 \mathrm{rpm}$ for $10 \mathrm{~min}$ & mirVana PARIS kit & cel-miR-39 \\
\hline Miyamae, $2015^{14}$ & Plasma & $\begin{array}{l}1500 \mathrm{rpm} \text { for } 30 \mathrm{~min}, 3000 \mathrm{rpm} \text { for } 5 \mathrm{~min} \text {, } \\
4500 \mathrm{rpm} \text { for } 5 \mathrm{~min}\end{array}$ & mirVana PARIS Kit & cel-miR-39 \\
\hline Komatsu, $2015^{15}$ & Plasma & $\begin{array}{l}1500 \mathrm{rpm} \text { for } 30 \mathrm{~min}, 3000 \mathrm{rpm} \text { for } 5 \mathrm{~min} \text {, } \\
4500 \mathrm{rpm} \text { for } 5 \mathrm{~min}\end{array}$ & mirVana PARIS Kit & cel-miR-39 \\
\hline Abue, $2015^{16}$ & Plasma & $3500 \mathrm{rpm}$ for $10 \mathrm{~min}$ & mirVana PARIS kit & miR-16 \\
\hline Zhang, $2014^{17}$ & Serum & NA & mirVana PARIS kit & U6 snRNA \\
\hline Slater, $2014^{18}$ & Serum & NA & miRNeasy Kit & miR-24 \\
\hline Lin, $2014^{19}$ & Serum & $1500 \mathrm{~g}$ for $10 \mathrm{~min}$ & miRNeasy Kit & cel-miR-39 \\
\hline Ganepola, $2014^{20}$ & Plasma & NA & TRI Reagent BD & miR-3196 \\
\hline Zhao, $2013^{21}$ & Serum & NA & mirVana PARIS kit & U6 snRNA \\
\hline $\mathrm{Li}, 2013^{22}$ & Serum & NA & mirVana PARIS kit & miR-16 \\
\hline Liu, R., $2012^{23}$ & Serum & $\begin{array}{l}800 \mathrm{~g} \text { for } 10 \mathrm{~min}, 10000 \mathrm{~g} \text { for } 15 \mathrm{~min}, 12000 \mathrm{~g} \text { for } \\
10 \mathrm{~min}, 16000 \mathrm{~g} \text { for } 20 \mathrm{~min}\end{array}$ & TRIzol Reagent & $\begin{array}{l}\text { normalized to the serum } \\
\text { volume }\end{array}$ \\
\hline
\end{tabular}


Table SI (Continued).

\begin{tabular}{|c|c|c|c|c|}
\hline Ref & Specimen & Centrifugation & Extraction & Normalization \\
\hline Liu, J., $2012^{24}$ & Plasma & $1200 \mathrm{~g}$ for $10 \mathrm{~min}, 12000 \mathrm{~g}$ for $10 \mathrm{~min}$ & TRI Reagent BD & cel-miR-39 \\
\hline Wang, $2009^{25}$ & Plasma & $1300 \mathrm{~g}$ for $10 \mathrm{~min}, 12000 \mathrm{~g}$ for $30 \mathrm{~min}$ & Trizol LS reagent & miR-16 \\
\hline Goto, $2018^{26}$ & Exosomes & $5000 \mathrm{~g}$ for $10 \mathrm{~min}$ & Trizol kit & $\begin{array}{l}\text { normalized to the serum } \\
\text { volume }\end{array}$ \\
\hline Hua, $2017^{27}$ & Serum & $3500 \mathrm{rpm}$ for $10 \mathrm{~min}$ & mirVana PARIS kit & U6 snRNA \\
\hline Imamura, $2017^{28}$ & Plasma & $\begin{array}{l}1500 \mathrm{rpm} \text { for } 30 \mathrm{~min}, 3000 \mathrm{rpm} \text { for } 5 \mathrm{~min} \text {, } \\
4500 \mathrm{rpm} \text { for } 5 \mathrm{~min}\end{array}$ & mirVana PARIS kit & cel-miR-39 \\
\hline Xu, Y., $2017^{29}$ & Exosomes & $\begin{array}{l}2000 \mathrm{rpm} \text { for } 15 \mathrm{~min}, 10000 \mathrm{~g} \text { for } 30 \mathrm{~min}, 10000 \mathrm{~g} \\
\text { for } \mathrm{lh}\end{array}$ & Trizol reagent & cel-miR-54 \\
\hline
\end{tabular}

Table S2 Summary of studies reporting diagnostic performance of miRNAs in miRNA panels with pancreatic cancer (only miRNAs that have been reported in $\geq 2$ panels)

\begin{tabular}{|c|c|c|c|c|c|c|c|c|c|c|}
\hline miRNA & $\begin{array}{l}\text { Franklin, } \\
2018^{6}\end{array}$ & $\begin{array}{l}\text { Duell, } \\
2017^{7}\end{array}$ & $\begin{array}{l}\text { Johansen, } \\
2016^{11}\end{array}$ & $\begin{array}{l}\text { Alemar, } \\
2016^{13}\end{array}$ & $\begin{array}{l}\text { Slater, } \\
2014^{18}\end{array}$ & $\begin{array}{l}\text { Ganepola, } \\
2014^{20}\end{array}$ & $\begin{array}{l}\text { Liu.R, } \\
2012^{23}\end{array}$ & $\begin{array}{l}\text { Liu.J.Q, } \\
201224\end{array}$ & $\begin{array}{l}\text { Wang, } \\
2009^{25}\end{array}$ & $\begin{array}{l}\text { Number } \\
\text { Of } \\
\text { Studies }\end{array}$ \\
\hline miR-2I & & $\circ \uparrow$ & & $\circ \uparrow$ & & & $\circ \uparrow$ & & $\circ \uparrow$ & 4 \\
\hline miR-24 & $\circ \uparrow$ & & ०- & & & & $\circ \uparrow$ & & & 3 \\
\hline miR-196a & & & & & $\circ \uparrow$ & & & $\circ \uparrow$ & $\circ \uparrow$ & 3 \\
\hline miR-106b & 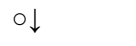 & $\circ \uparrow$ & & & & & & & & 2 \\
\hline $\mathrm{miR}-25$ & & & ०- & & & & $\circ \uparrow$ & & & 2 \\
\hline miR-I55 & & $\circ \uparrow$ & & & & & & & $\circ \uparrow$ & 2 \\
\hline miR-34a & $\circ \uparrow$ & & & $\circ \uparrow$ & & & & & & 2 \\
\hline miR-I9I & & & ० & & & & $\circ \uparrow$ & & & 2 \\
\hline miR-20a & & & O- & & & & $\circ \uparrow$ & & & 2 \\
\hline miR-885-5p & $\circ \uparrow$ & & & & & $\circ \uparrow$ & & & & 2 \\
\hline
\end{tabular}

Notes: $\circ$ represents miRNAs which are part of a panel; $\uparrow$ represents upregulation; $\downarrow$ represents down-regulation; - represents no difference in overall study population.

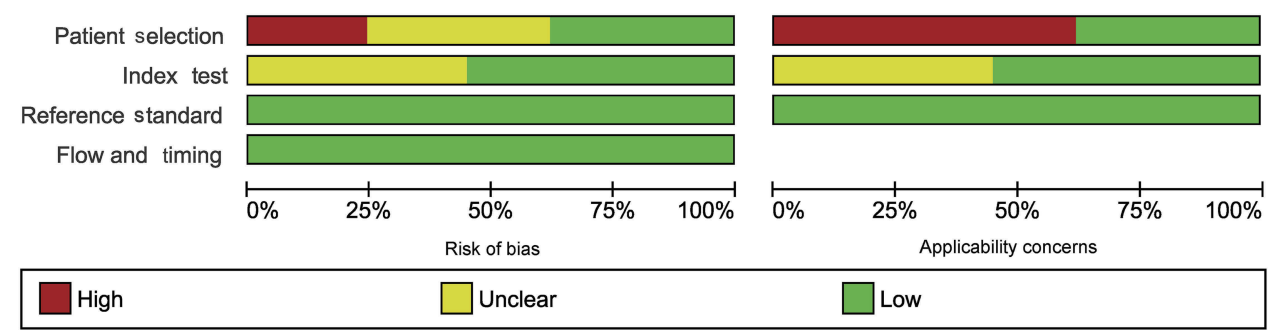

Figure SI Risk of bias and applicability concerns graph: review authors' judgements about each domain presented as percentages across included studies. 


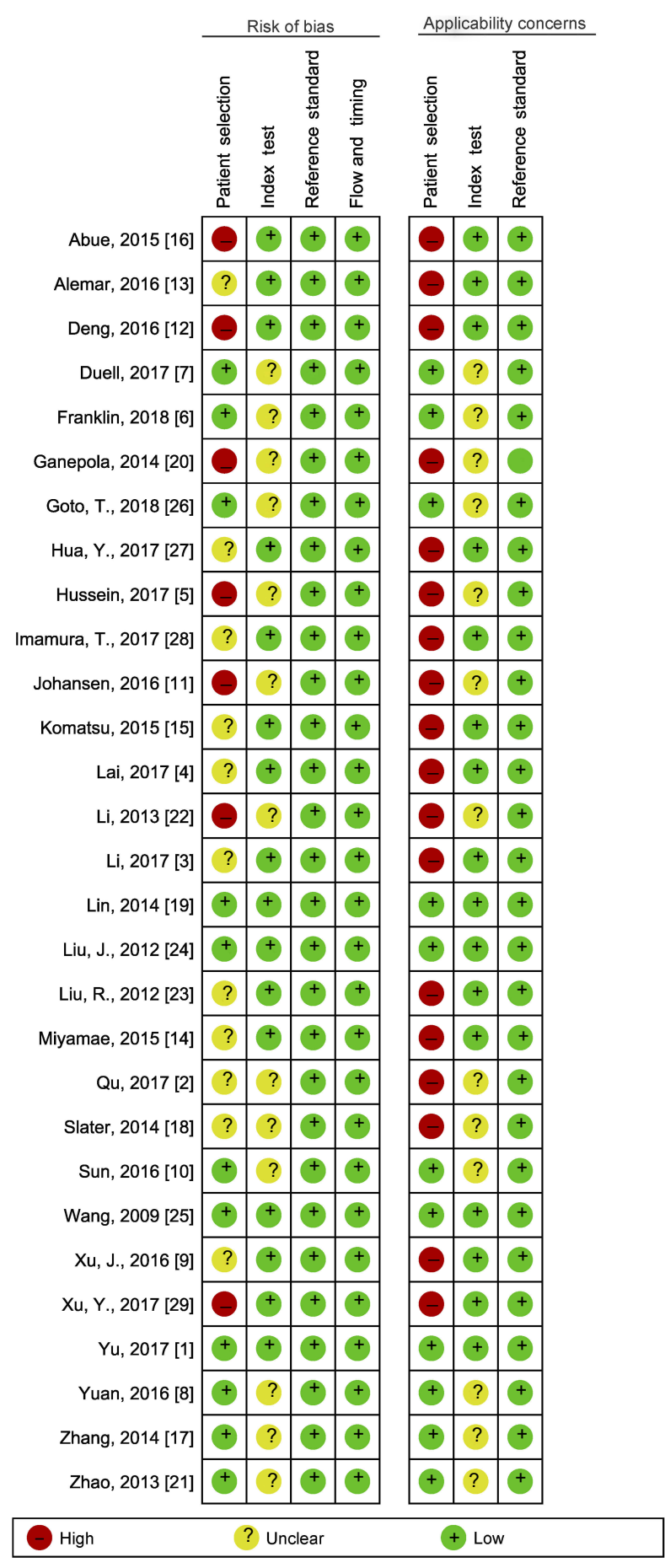

Figure S2 Risk of bias and applicability concerns summary: review authors' judgements about each domain for each included study.

\section{References}

1. Yu Q, Xu C, Yuan W, et al. Evaluation of plasma MicroRNAs as diagnostic and prognostic biomarkers in pancreatic adenocarcinoma: miR-196a and miR-210 Could be negative and positive prognostic markers, respectively. Biomed Res Int. 2017;2017:6495867. doi: $10.1155 / 2017 / 6495867$
2. Qu K, Zhang X, Lin T, et al. Circulating miRNA-21-5p as a diagnostic biomarker for pancreatic cancer: evidence from comprehensive miRNA expression profiling analysis and clinical validation. Sci Rep. 2017;7(1):1692. doi:10.1038/s41598-017-01904-Z

3. Li F, Xu JW, Wang L, Liu H, Yan Y, Hu SY MicroRNA-221-3p is up-regulated and serves as a potential biomarker in pancreatic cancer. Artif Cells Nanomed Biotechnol. 2018;46(3):482-487. doi:10.1080/ 21691401.2017.1315429

4. Lai X, Wang M, McElyea SD, Sherman S, House M, Korc M A microRNA signature in circulating exosomes is superior to exosomal glypican-1 levels for diagnosing pancreatic cancer. Cancer Lett. 2017;393:86-93. doi:10.1016/j.canlet.2017.02.019

5. Hussein NA, Kholy ZA, Anwar MM, Ahmad MA, Ahmad SM Plasma miR-22-3p, miR-642b-3p and miR-885-5p as diagnostic biomarkers for pancreatic cancer. J Cancer Res Clin Oncol. 2017;143 (1):83-93. doi:10.1007/s00432-016-2248-7

6. Franklin O, Jonsson P, Billing O, et al. Plasma micro-RNA alterations appear late in pancreatic cancer. Ann Surg. 2018;267(4):775-781. doi:10.1097/SLA.0000000000002124

7. Duell EJ, Lujan-Barroso L, Sala N, et al. Plasma microRNAs as biomarkers of pancreatic cancer risk in a prospective cohort study. Int J Cancer. 2017;141(5):905-915. doi:10.1002/ijc.30790

8. Yuan W, Tang W, Xie Y, et al. New combined microRNA and protein plasmatic biomarker panel for pancreatic cancer. Oncotarget. 2016;7 (48):80033-80045. doi:10.18632/oncotarget.12406

9. Xu J, Cao Z, Liu W, et al. Plasma miRNAs effectively distinguish patients with pancreatic cancer from controls: a multicenter study. Ann Surg. 2016;263(6):1173-1179.

10. Sun B, Liu X, Gao Y, Li L, Dong Z Downregulation of miR-124 predicts poor prognosis in pancreatic ductal adenocarcinoma patients. Br J Biomed Sci. 2016;73(4):152-157. doi:10.1080/09674845.2016. 1220706

11. Johansen JS, Calatayud D, Albieri V, et al. The potential diagnostic value of serum microRNA signature in patients with pancreatic cancer. Int J Cancer. 2016;139(10):2312-2324. doi:10.1002/ijc.30291

12. Deng T, Yuan Y, Zhang C, et al. Identification of circulating MiR-25 as a potential biomarker for pancreatic cancer diagnosis. Cell Physiol Biochem. 2016;39(5):1716-1722. doi:10.1159/000447872

13. Alemar B, Izetti P, Gregorio C, et al. miRNA-21 and miRNA-34a are potential minimally invasive biomarkers for the diagnosis of pancreatic ductal adenocarcinoma. Pancreas. 2016;45(1):84-92. doi:10.10 97/MPA.0000000000000383

14. Miyamae M, Komatsu S, Ichikawa D, et al. Plasma microRNA profiles: identification of miR-744 as a novel diagnostic and prognostic biomarker in pancreatic cancer. $B r J$ Cancer. 2015;113 (10):1467-1476. doi:10.1038/bjc.2015.366

15. Komatsu S, Ichikawa D, Miyamae M, et al. Malignant potential in pancreatic neoplasm; new insights provided by circulating miR-223 in plasma. Expert Opin Biol Ther. 2015;15(6):773-785. doi:10.1517/ 14712598.2015.1029914

16. Abue M, Yokoyama M, Shibuya R, et al. Circulating miR-483-3p and miR-21 is highly expressed in plasma of pancreatic cancer. Int $J$ Oncol. 2015;46(2):539-547. doi:10.3892/ijo.2014.2743

17. Zhang J, Zhao CY, Zhang SH, et al. Upregulation of miR-194 contributes to tumor growth and progression in pancreatic ductal adenocarcinoma. Oncol Rep. 2014;31(3):1157-1164. doi:10.3892/or.2013.2960

18. Slater EP, Strauch K, Rospleszcz S, et al. MicroRNA-196a and-196b as potential biomarkers for the early detection of familial pancreatic cancer. Transl Oncol. 2014;7(4):464-471. doi:10.1016/j.tranon.2014.05.007

19. Lin MS, Chen WC, Huang JX, Gao HJ, Sheng HH Aberrant expression of microRNAs in serum may identify individuals with pancreatic cancer. Int J Clin Exp Med. 2014;7(12):5226-5234.

20. Ganepola GAP, Rutledge JR, Suman P, Yiengpruksawan A, Chang DH Novel blood-based microRNA biomarker panel for early diagnosis of pancreatic cancer. World J Gastro Oncol. 2014;6(1):22-33. doi:10.4251/wjgo.v6.i1.22 
21. Zhao C, Zhang J, Zhang S, et al. Diagnostic and biological significance of microRNA-192 in pancreatic ductal adenocarcinoma. Oncol Rep. 2013;30(1):276-284. doi:10.3892/or.2013.2420

22. Li A, Yu J, Kim H, et al. MicroRNA array analysis finds elevated serum miR-1290 accurately distinguishes patients with low-stage pancreatic cancer from healthy and disease controls. Clin Cancer Res. 2013;19(13):3600-3610. doi:10.1158/1078-0432.CCR-12-3092

23. Liu R, Chen X, Du YQ, et al. Serum microRNA expression profile as a biomarker in the diagnosis and prognosis of pancreatic cancer. Clin Chem. 2012;58(3):610-618. doi:10.1373/clinchem.2011.172767

24. Liu JQ, Gao J, Du YQ, et al. Combination of plasma microRNAs with serum CA19-9 for early detection of pancreatic cancer. Int $J$ Cancer. 2012;131(3):683-691. doi:10.1002/ijc.26422

25. Wang J, Chen JY, Chang P, et al. MicroRNAs in plasma of pancreatic ductal adenocarcinoma patients as novel blood-based biomarkers of disease. Cancer Prev Res (Phila). 2009;2(9):807-813. doi:10.1158/ 1940-6207.CAPR-09-0094
26. Goto T, Fujiya M, Konishi H, et al. An elevated expression of serum exosomal microRNA-191, - 21, -451 a of pancreatic neoplasm is considered to be efficient diagnostic marker. BMC Cancer. 2018;18 (1):116. doi: $10.1186 / \mathrm{s} 12885-018-4242-8$

27. Hua Y, Chen H, Wang L, et al. Low serum miR-373 predicts poor prognosis in patients with pancreatic cancer. Cancer Biomarkers. 2017;20(1):95-100. doi:10.3233/CBM-170231

28. Imamura T, Komatsu S, Ichikawa D, et al. Depleted tumor suppressor miR-107 in plasma relates to tumor progression and is a novel therapeutic target in pancreatic cancer. Sci Rep. 2017;7(1):5708. doi:10.1038/s41598-017-06137-8

29. Xu YF, Hannafon BN, Zhao YD, Postier RG, Ding WQ Plasma exosome miR-196a and miR-1246 are potential indicators of localized pancreatic cancer. Oncotarget. 2017;8(44):77028-77040. doi:10.18632/oncotarget.20332

\section{Publish your work in this journal}

OncoTargets and Therapy is an international, peer-reviewed, open access journal focusing on the pathological basis of all cancers, potential targets for therapy and treatment protocols employed to improve the management of cancer patients. The journal also focuses on the impact of management programs and new therapeutic agents and protocols on patient perspectives such as quality of life, adherence and satisfaction. The manuscript management system is completely online and includes a very quick and fair peer-review system, which is all easy to use. Visit http://www.dovepress.com/ testimonials.php to read real quotes from published authors. 